\title{
Various Explanations for the Phenomenon of Low Voltage in Patients with Hypothyroidism
}

\author{
F. Cuculia P. Erne \\ ${ }^{a}$ Department of Cardiology, John Radcliffe Hospital, Oxford, UK; ${ }^{b}$ Department of Cardiology, \\ Luzerner Kantonsspital, Luzern, Switzerland
}

We read with interest the study by Yamanaka et al. [1], which demonstrated that in patients with hypothyroidism, attenuated QRS voltage is related to the presence of pericardial effusion and the severity of hypothyroidism. Additionally, there was a non-significant trend toward lower albumin levels in patients with low voltage.

Attenuation of voltage can have various reasons and different pathophysiologic explanations. According to Ohm's law, voltage is inversely proportional to resistance. Pericardial effusion clearly increases resistance and can explain low voltage although little is known to what extent the volume and composition of the effusion affects voltage. Another reason for increased resistance could be oedema in the tissues between the myocardium and the ECG electrode. It is well known that severe hypothyroidism is associated with pretibial myxoedema, but massive lymphoedema has been described in different body parts in the past [2]. We recently demonstrated temporary loss of voltage after defibrillation or cardioversion [3] and believe that temporary skin oedema in the precordial region could have explained this phenomenon.

In patients with isolated (or predominant) precordial low voltage anatomical factors should also be taken into consid- eration. We assessed the phenomenon of low voltage in patients with ascites and demonstrated that attenuated voltage could be partially corrected if the precordial electrodes were placed one or two intercostal spaces cranially [4]. Having in mind that severe hypothyroidism is associated with ascites [5] and that there was a trend toward lower albumin values in the study by Yamanaka et al. [1], we believe that the presence of ascites should be actively assessed when severely hypothyroid patients are diagnosed with low voltage. As demonstrated in our study, drainage of ascites normalizes the ECG in these patients.

\section{References}

Yamanaka S, Kumon Y, Matsumura Y, Kamioka M, Takeuchi H, Sugiura T: Link between pericardial effusion and attenuation of QRS voltage in patients with hypothyroidism. Cardiology 2010;116:32-36.

2 Wu D, Gibbs J, Corral D, Intengan M, Brooks JJ: Massive localized lymphedema: additional locations and association with hypothyroidism. Hum Pathol 2000;31:1162-1168.

3 Cuculi F, Kobza R, Erne P: ECG changes following cardioversion and defibrillation. Swiss Med Wkly 2007;137:551-555.
Cuculi F, Jamshidi P, Kobza R, Rohacek M, Erne P: Precordial low voltage in patients with ascites. Europace 2008;10:96-98.

5 Ji JS, Chae HS, Cho YS, Kim HK, Kim SS, Kim CW, Lee CD, Lee BI, Choi H, Lee KM, Lee HK, Choi KY: Myxedema ascites: case report and literature review. J Korean Med Sci 2006;21:761-764.

\section{KARGER}

Fax +4161306 1234 E-Mail karger@karger.ch www.karger.com
Dr. Florim Cuculi

Department of Cardiology

John Radcliffe Hospital, Headley Way, Oxford OX3 9DU (UK)

Tel. +44 186557 2590, Fax +44 186522 0585, E-Mail florim@gmx.net 